\title{
Epidemiological Influences and Requirements of Global Childhood Obesity Research
}

\author{
Doris Klingelhöfer Markus Braun David Quarcoo Dörthe Brüggmann \\ David Alexander Groneberg \\ Institute of Occupational, Social and Environmental Medicine, Goethe University, Frankfurt, Germany
}

\section{Keywords}

Child adiposity · Global health · Prevalence · Public health ·

Publication output

\begin{abstract}
Introduction: Obesity is classified as a global epidemic and judged to be the greatest public health threat in Western countries. The tremendously increasing prevalence rates in children lead to morbidity and mortality in adults. In many countries, prevalence has doubled since the 1980s. Other countries show a continuous increase or stagnate at a very high level. Given these regional differences, this study aims to draw a global world map of childhood obesity research, including regional epidemiological characteristics, to comprehensively assess research influences and needs. Methods: In addition to established bibliometric parameters, this study uses epidemiological data to interpret metadata on childhood obesity research from the Web of Science in combination with state-of-the-art visualization methods, such as density equalizing map projections. Results: It was not until the 1990s that belated recognition of the dangerous effects of childhood obesity led to an increase in the number of publications worldwide. In addition, our findings show that countries' study output does not correlate with epidemiologic rates of childhood obesity. In contrast, the primary driv-
\end{abstract}

karger@karger.com www.karger.com/ofa

Karger $\stackrel{\text { ' }}{5}$

GOPEN ACCESS
(C) 2021 The Author(s)

Published by S. Karger AG, Basel

This is an Open Access article licensed under the Creative Commons Attribution-NonCommercial-4.0 International License (CC BY-NC) (http://www.karger.com/Services/OpenAccessLicense), applicable to the online version of the article only. Usage and distribution for commercial purposes requires written permission. er of the research efforts on childhood obesity appears to be largely driven government funding structures. Discussion/ Conclusion: The geographical differences in the epidemiological background of childhood obesity complicate the implementation of transnational research projects and crossborder prevention programs. Effective realization requires a sound scientific basis, which is facilitated by globally valid approaches. Hence, there is a need for information exchange between researchers, policy makers, and private initiatives worldwide.

(c) 2021 The Author(s)

Published by S. Karger AG, Basel

\section{Introduction}

Obesity is a major health threat and a serious public health problem around the world. As early as in 2002, it was declared as a global epidemic by the WHO [1] and ranked as the greatest threat to the Western world by the OECD [2]. It often manifests itself already in childhood and leads to severe adverse health impairments in later years, which are not seldom life threatening. The numbers and their increase are alarming [3]. In 2016, 50 million girls and 74 million boys worldwide suffered from obesity [4]. In $>70$ countries, prevalence has doubled 
since the 1980s. Many other countries show a steady increase. Although at high levels, the increase in BMI has leveled off only among girls in high-income regions and in some parts of Latin America. In contrast, the increase in obesity among all children in East, South, and SouthEast Asia accelerated and initially correlated with the trend of adult obesity. Since 2000, this correlation is no longer significant [4].

From 1975 to 2016, global prevalence (age standardized) increased from 0.7 to $5.6 \%$ for girls and from 0.9 to $7.8 \%$ for boys [4]. In 2016, prevalence rates exceeded $30 \%$ in some South Pacific Islands and $20 \%$ in parts of Polynesia, Micronesia, the Caribbean, several Middle Eastern countries, and in parts of the USA [4]. The prevalence of childhood obesity is lower in middle and high socioeconomic classes in developed countries, while these classes are more affected in developing countries [5].

The increase in prevalence rates among children and adolescents is accompanied by an increase in comorbid conditions [6]. These cover many different diseases ranging from cardiovascular, pulmonary, and endocrine effects to psychological (discrimination, low self-esteem, and depression) [7] and functional impairments, to name a few [8]. Diseases such as type 2 diabetes, which normally only occur in adulthood, are now already appearing in childhood [6]. Therefore, preventing exaggerated weight gain in childhood is critical to minimize, partly because of the enormous economic and societal burdens caused by obesity.

These alarming epidemiological data on childhood obesity are influenced by several factors. Changing eating habits and the reduction of physical activity lead to a diet that exceeds caloric requirement [9]. This demonstrates the influences of ethnic group affiliation [10].

Studies suggest that there is also an association between genetic factors and the development of obesity in $40-85 \%$ of cases, although the mechanisms are still unclear $[11,12]$. However, genetics can only determine a predisposition, but environmental and social factors cause obesity.

A recent epigenetic study published in Nature shows for the first time the relationship between the amount of brown adipose tissue and BMI, as well as the influence of the season of conception, that is, a positive correlation between the presence of brown adipose tissue of the newborn and low ambient temperature at the time of conception [13].

Although many studies have been conducted on childhood obesity, the impacts, trends, and burdens of the disease remain unclear [3]. Findings from studies are diffi- cult to compare because the definition of obesity varies [14]. Besides, substantial international differences in physical development complicate the comparison and evaluation of studies [1].

To provide the background information necessary to facilitate the planning and implementation of meaningful projects and programs, we selected global research on childhood obesity for an in-depth publication analysis. For this purpose, in addition to applying established general parameters, epidemiologic data on childhood obesity were included to determine how these characteristics influence the publication landscape and to assess whether they have been adequately addressed to date.

\section{Methods}

\section{Methodological Platform}

When evaluating a large amount of publication data, bibliometric analyses are essential and have proven to be a reliable assessment tool for research output on specific scientific topics [15]. The New Quality and Quantity Indices in Science platform was launched to provide substantial information on conditions, influences, implications, and trends in the field of biomedicine [16]. Since 2009, a large number of analyses were carried out in this respect, providing new insights into the global contexts of research and its output [17-19].

\section{Data Source and Search Strategy}

All bibliometric data were retrieved from the Web of Science (WoS). This scientific literature database provides not only the international works and their metadata but also their citation numbers, so quantitative and qualitative evaluations are possible. This is because the number of citations is an important parameter for assessing the awareness and influence of scientific publications [15]. The evaluation period was set from 1900 until 2017. Only original articles were included in the search.

The following string term was used for searching in WoS: "(obesity OR obese OR adiposit* OR overweight OR fatness OR "skinfold thickness" OR bariatric* OR "body weight") AND (child* OR infant* OR infanc* OR boy* OR girl*) Not pregnan*." The term "pregnan*" summarizes articles dealing with pregnancy (pregnant), and the Boolean operator "not" excludes them from the search. Analysis of entries found without the exclusion of pregnancy-related articles revealed a majority of entries that did not relate to childhood obesity. Instead, most of these articles address obese women in pregnancy. After downloading the bibliometric data, a database was created, which was expanded and partially manually adjusted.

\section{Analyses}

The dataset was analyzed according to chronological and geographical parameters. Quantitative and qualitative approaches were applied. The total number of publications and collaboration articles was analyzed according to their development over time and according to the performance of countries publishing on childhood obesity. Citation parameters were used to assess the in- 


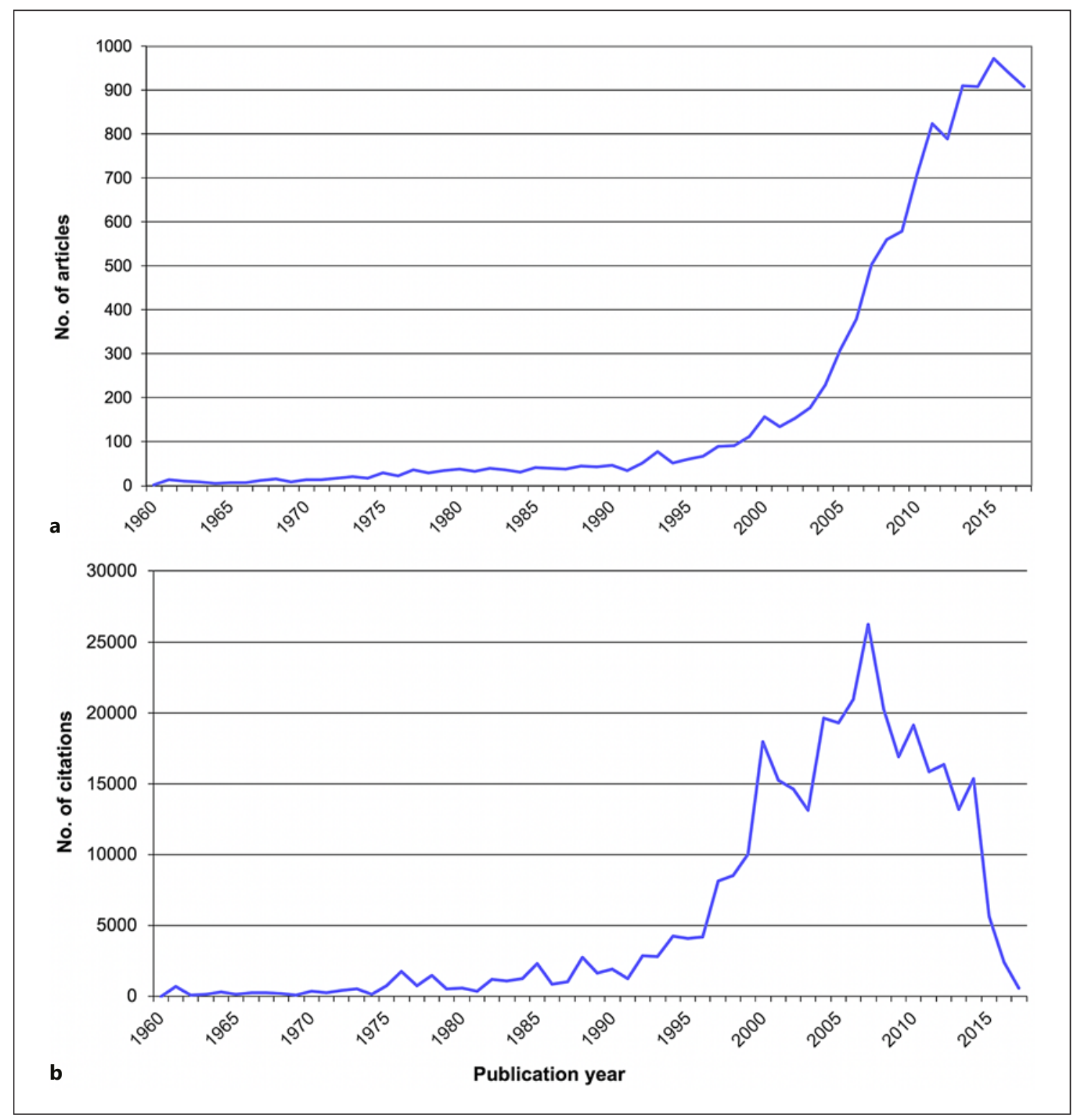

Fig. 1. Publication numbers from 1960 until 2017. a Number of articles. b Number of citations.

ternational recognition of the countries' publication output. Epidemiological parameters were included to assess the regional performance compared with the burden of childhood obesity. The findings were brought into relation with the prevalence rates of publishing countries. A threshold of at least 30 articles was set in the analyses of ratios to avoid bias from countries that have published very little on childhood obesity.

\section{Visualization}

Some of the results were visualized using density equalizing map projections, a method that distorts the world map according to the analysis parameters. In this method, countries with small numbers will be reduced, and countries with large numbers will be inflated according to their size. This process is determined by the diffusion equilibrium [20].

\section{Data Statement}

The bibliometric data are owned by and have been obtained from the WoS database. Any researcher with access to the WoS database can obtain the data using the methods described in the study. Readers who do not have access to WoS should contact Clarivate Analytics to obtain a license. As per Clarivate Analytics terms of use, authors may also be able to obtain limited access to data, subject to their agreement. 
Table 1. The 10 most cited articles on children obesity in WoS

\begin{tabular}{|c|c|c|c|c|}
\hline Country & Authors & Year & Citations & Title \\
\hline UK, USA & Cole T.J., Bellizzi M.C., Flegal K.M., et al. & 2000 & 7,967 & $\begin{array}{l}\text { "Establishing a Standard Definition for Child Overweight and } \\
\text { Obesity Worldwide: International Survey" }\end{array}$ \\
\hline USA & Hedley A.A., Ogden C.L., Johnson C.L., et al. & 2004 & 2,901 & $\begin{array}{l}\text { "Prevalence of Overweight and Obesity among US Children, } \\
\text { Adolescents, and Adults, 1999-2002" }\end{array}$ \\
\hline $\begin{array}{l}\text { USA, Italy, } \\
\text { Ethiopia + others }\end{array}$ & Ng M., Fleming T., Robinson M., et al. & 2014 & 2,468 & $\begin{array}{l}\text { "Global, Regional, and National Prevalence of Overweight and } \\
\text { Obesity in Children and Adults during 1980-2013: A Systematic } \\
\text { Analysis for the Global Burden of Disease Study 2013" }\end{array}$ \\
\hline USA & Whitaker R.C. Wright, Pepe M.S., et al. & 1997 & 2,419 & $\begin{array}{l}\text { "Predicting Obesity in Young Adulthood from Childhood and } \\
\text { Parental Obesity" }\end{array}$ \\
\hline $\begin{array}{l}\text { UK, Finland, } \\
\text { USA }\end{array}$ & $\begin{array}{l}\text { Frayling T.M., Timpson N.J., Weedon M.N., } \\
\text { et al. }\end{array}$ & 2007 & 2,303 & $\begin{array}{l}\text { "A Common Variant in the FTO Gene Is Associated with Body } \\
\text { Mass Index and Predisposes to Childhood and Adult Obesity" }\end{array}$ \\
\hline USA & Weiss R., Dziura J., Burgert T.S., et al. & 2004 & 1,885 & $\begin{array}{l}\text { "Obesity and the Metabolic Syndrome in Children and } \\
\text { Adolescents" }\end{array}$ \\
\hline
\end{tabular}

WoS, Web of Science.

\section{Results}

A total of 11,694 articles $(n)$ could be retrieved from WoS that were related to childhood obesity from 1901 until 2017. Of these, the absolute majority $(n=11,018$, 94.22\%) were written in English.

\section{Development of Publication Output}

The first article on the relationship between food intake and body weight in children was published in 1901 [21]; 20 years later, the next article mentioned obesity in its title. Subsequently, the publication numbers remained in the single digits until the 1960s, when double-digit numbers were reached. Thereafter, the numbers increased slightly, and since the mid-90s, more and more steeply until the current maximum in 2015 with 972 articles (Fig. 1a). With small peaks, citation numbers (c) remained similarly low until the mid-90s. Two maximums of citation numbers can be seen in 2000 ( $c=$ $17,960)$ and $2007(c=26,260)$. Since 2007, the number of citations has dropped significantly to 563 citations in 2017 (Fig. 1b). The citation peaks are in line with highly prolific articles in the respective years (Table 1). The most cited article was published in 2000. In this study, Cole et al. [22] established a standard definition for over- weight children. Two other high-impact articles contributed to the citation maximum of 2007. In the first article, the association of a genetic variant and obesity was found [11]. In the second article, a panel of experts provided recommendations for the prevention and treatment of childhood obesity [23]. Besides, studies on prevalence rates are of high interest and are represented among the most cited articles.

\section{Countries' Contribution}

Since 1973, almost complete information about the countries of origin could be retrieved via the metadata of articles, so that 11,448 articles $(97.90 \%)$ could be evaluated according to their countries of origin. This database sets the framework for all geographical analyses. All $n=$ 246 articles without indication of country of origin date from before 1973.

The USA contributed to $36.84 \%$ of all articles evaluated $(n=4,218)$, making it the country with the most articles on childhood obesity (Fig. 2a). The UK was the country with the second most publications $(n=1,067)$, followed by Germany $(n=831)$, Australia $(n=645)$, and Italy $(n=618)$. Looking at the development over time, the participation shares have changed (Fig. 2b). Although the USA retained the first position, its share decreased from 


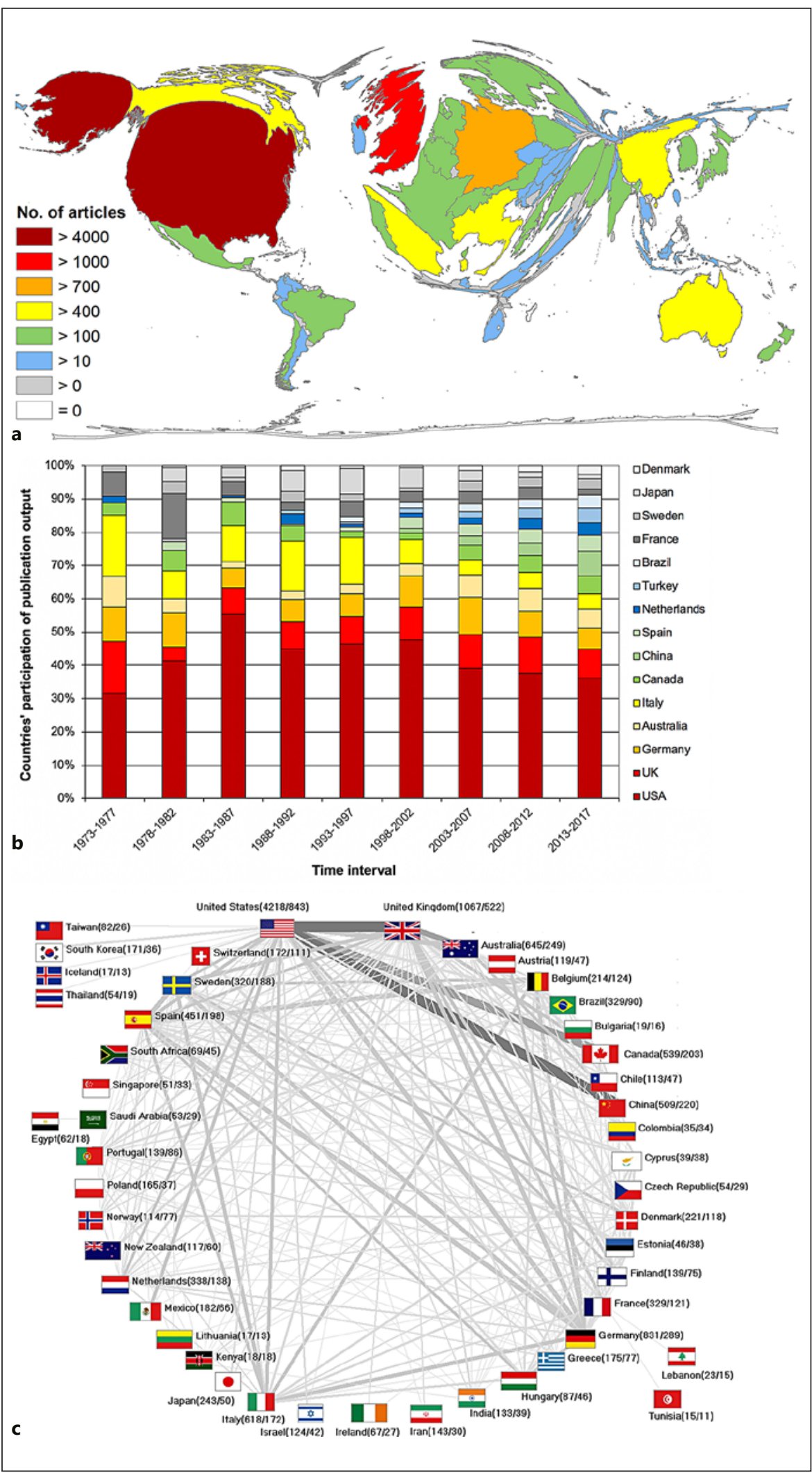

Fig. 2. Countries' publication performance. a Global density equalizing map projection. b Development of the 15 most publishing countries' share over time. c International network (number of articles/ number of collaboration articles). 


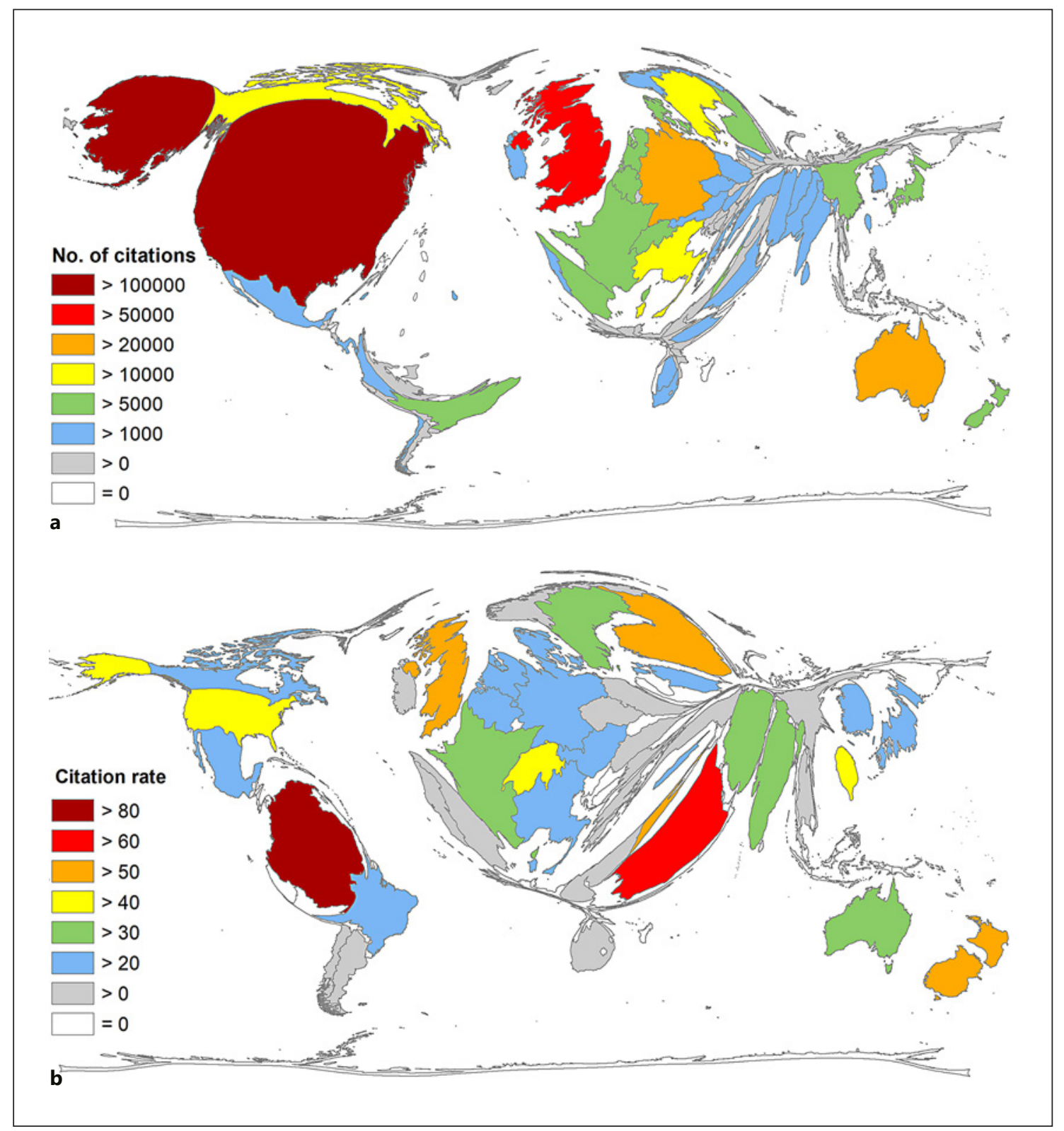

Fig. 3. Citation parameter of the publication output on childhood obesity. a Number of citations. b Citation rate. Threshold $=30$ articles.

$55.42(1983-1987)$ to $36.16 \%$. China reached third rank from 2013 onward.

\section{International Collaborations}

Even though the number of international collaborations increased considerably from initial single-digit figures to $>200$ collaboration articles per year, the absolute share is relatively low at $17.35 \%(n=1,987)$. With 1,012 affiliations from 108 countries, the study from the Non-
Communicable Diseases Risk Factor Collaboration (NCD-RisC), which evaluated 128.9 million children, is by far the strongest cooperation of this analysis [4]. The GBD 2015 Obesity Collaborators, coordinated by the American Institute for Health Metrics and Evaluation (IHME), also have a high number of partner countries. They conducted a study of health effects in 195 countries from 1980 to 2015 [3]. Here, 146 affiliations from 46 countries participated in the analyses of 68.5 million persons. 
Fig. 4. Author's keywords; minimum number of entries $=70$. a Clusters of keywords. b Development over time. c Citation numbers.

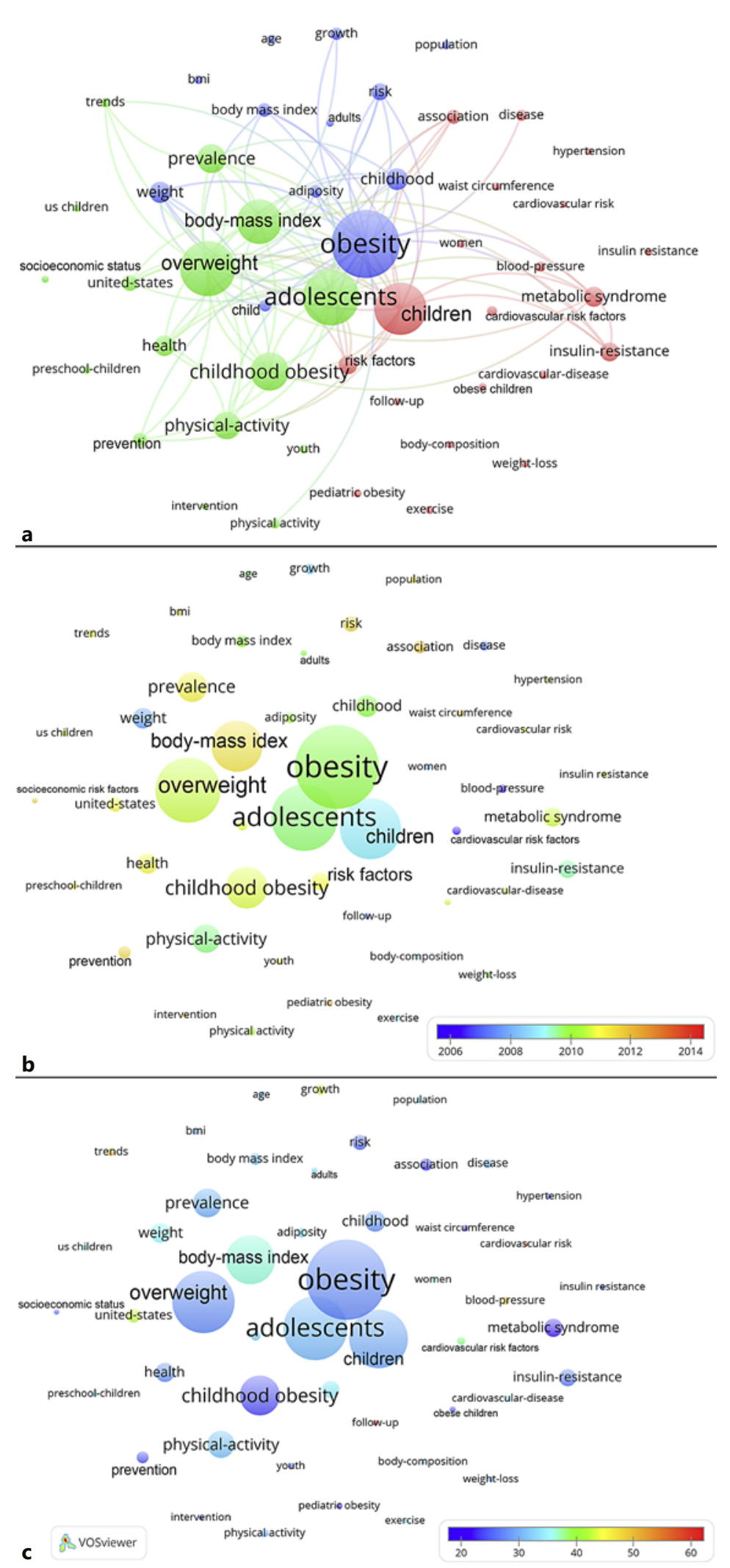


Over time, a multinational network has been established with the USA as the main collaboration country. Primarily, the USA collaborated with the UK $(n=139)$, China $(n=131)$, and Canada $(n=98)$. Nevertheless, the share of collaborations in the total amount of US articles was very low compared to other countries, at $19.98 \%$. In contrast, the UK collaborated in $48.89 \%$ of their obesity studies with other countries, China in $43.22 \%$, and Germany in $34.77 \%$ of their total work (Fig. 2c).

\section{Citation Parameters}

The comparison of the citation numbers $(c)$ received by each publishing country (Fig. 3a) more or less follows the distribution of the absolute publication numbers. The only difference is that the dominance of the Western world becomes even more apparent. The USA received 192,777 citations and the UK 56,867, followed by Germany $(c=23,291)$, Australia $(c=20,229)$, and Italy in the fifth place $(c=18,213)$. A different picture emerges when analyzing the citation rates (cr) of countries with $>30$ articles (threshold) published on the topic of childhood obesity. Here, Colombia is the leading country with $\mathrm{cr}=$ 87.63, followed by Saudi Arabia $(\mathrm{cr}=60.43)$, Finland $(\mathrm{cr}=53.47)$, UK $(\mathrm{cr}=53.30)$, and New Zealand $(\mathrm{cr}=$ 50.53) (Fig. 3b).

\section{Author's Keywords and Research Areas}

The findings of the author's keyword analysis revealed 3 different clusters (Fig. 4a). First, all topics related to the different categories of affected persons were addressed (blue). Second, epidemiological topics (green), such as prevalence, trends, and socioeconomic status, could be clustered, and third, risk factors and comorbidities formed another cluster (red). However, most of the entries were assigned to the terms of disease. Metabolic syndrome and insulin resistance, on the one hand, and physical activity and prevalence, on the other hand, were also more frequently addressed. Looking at the development over time of the keywords (Fig. 4b), some topics were used more recently, such as prevention, risk, associations, intervention, or pediatric obesity. The citation analysis revealed that some less added keywords like follow-up, trends, cardiovascular risk, and blood pressure were cited more than the others (Fig. 4c).

Analysis of WoS categories showed Pediatrics ( $n=$ $3,148)$ and Nutrition/Dietetics (N/D) $(n=2,552)$ as the most assigned research areas, followed by Endocrinology/Metabolism (E/M) $(n=2,336)$ and Public, Environmental, and Occupational Health $(\mathrm{PEOH})(n=1,740)$. The proportions changed over time (Fig. 5a). While
PEOH was increasingly assigned (7.46-18.33\%), the primary area Pediatrics decreased in terms of its relative proportion (41.79-25.20\%). N/D came more into research focus in the 1980s (33.22\%) but has decreased in the 21 st century (17.40\%). E/M got its largest share around the turn of the millennium (27.52\%) and decreased to $17.04 \%$ thereafter. The distribution of the most frequently assigned subject areas in the publishing countries also differs (Fig. 5b). The 4 areas concerned were principally balanced in the USA, the UK, Canada, and the Netherlands. However, in China and Turkey, N/D played a smaller role. In Italy and Turkey, $\mathrm{PEOH}$ was much less represented, and $\mathrm{E} / \mathrm{M}$ was relatively more assigned.

\section{Epidemiological Aspects}

When looking at the change in childhood obesity prevalence in countries with $>30$ articles (threshold), Saudi Arabia stood out with an increase of $9.33 \%$ (girls) and $8.52 \%$ (boys) from 1980 to 2015 . The second highest change was found in the USA with $7.29 \%$ for girls and $7.99 \%$ for boys. Egypt (6.76\%), Brazil (5.70\%), and Mexico (5.56\%) followed in prevalence change of girls. Regarding the increase of prevalence rates of boys, Brazil ranked third (7.69\%), followed by Canada (6.73\%), Egypt (6.67\%), Austria (5.96\%), Turkey (5.34\%), Portugal (5.28\%), China (5.11\%), and Greece (5.01\%). Figure 6 presents the results of the NCD-RisC [4] for girls (Fig. 6a) and boys (Fig. 6b) as density equalizing map projections.

Figure 7a shows the global prevalence rates and highlights the enormous prevalence rates of Caribbean, Polynesian, and Middle East countries [4, 24]. The sex-standardized prevalence rates of both genders $[4,24]$ among countries with $>30$ articles on childhood obesity (threshold) showed that Saudi Arabia (12.70\%) and the USA (12.41\%) are the most affected countries (Fig. 7b). A prevalence of $>10 \%$ is found in Canada $(10.88 \%)$, Chile (10.41\%), Egypt (10.20\%), and Greece (10.04\%). Evaluation of the ratio of the number of articles on childhood obesity and the prevalence of the countries with at least 30 articles $\left(R_{\text {PREV }}\right)$ shows the USA in the lead $\left(R_{\mathrm{PREV}}=\right.$ $332.11)$, followed by Germany $\left(R_{\mathrm{PREV}}=149.71\right)$, the UK $\left(R_{\mathrm{PREV}}=142.11\right)$, China $\left(R_{\mathrm{PREV}}=99.09\right)$, and Italy $\left(R_{\mathrm{PREV}}\right.$ =94.20) (Fig. 7C). While the linear regression of the country funding parameter "expenditures on research and development (R\&D)" for OECD countries [25] (Fig. 8a) and the number of articles on childhood obesity with $r^{2}=0.59$ was highly significant $(* * * p<0.0001)$, the linear regression between prevalence of childhood obe- 


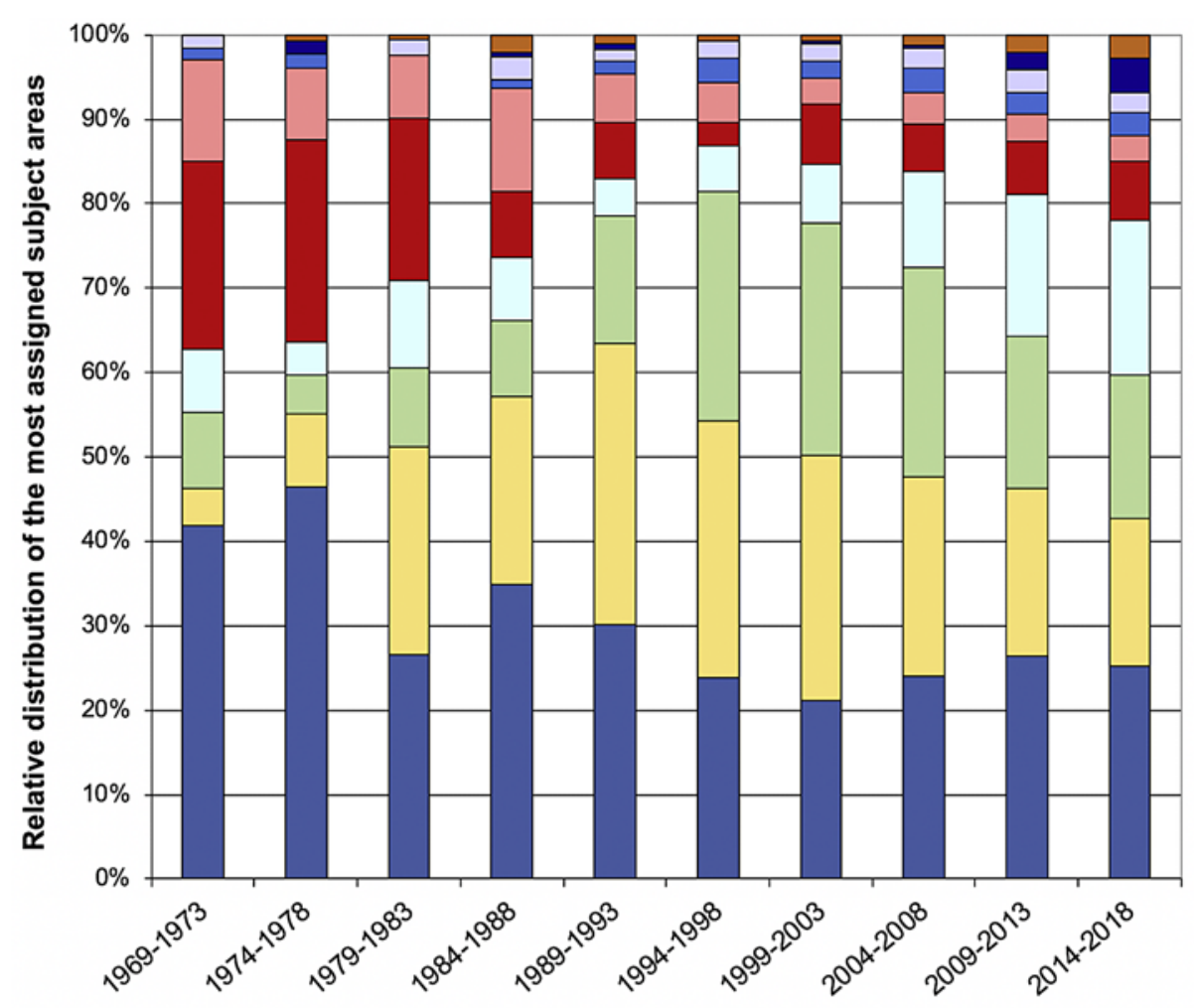

घResearch \& Experimental Medicine

- Science \& Technology - Other Topics

๑Cardiovascular System \& Cardiology

घSport Sciences

口Psychology

-General \& Intemal Medicine

口Public, Environmental \& Occupational Health

口Endocrinology \& Metabolism

口Nutrition \& Dietetics

aPediatrics

a

Time interval

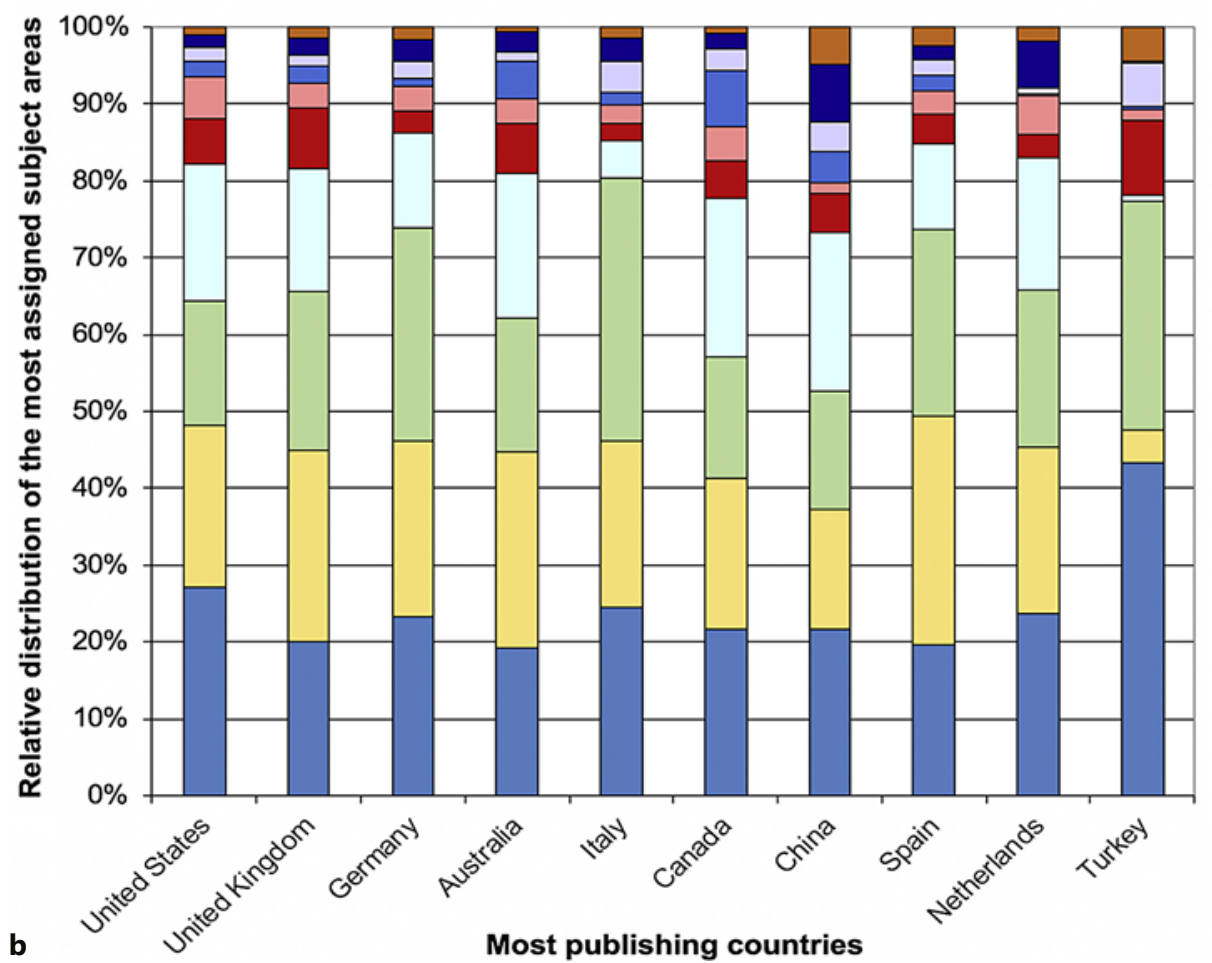

Fig. 5. Distribution of the most assigned subject areas. a Chronological changes in 5-year intervals from 1969 to 2018. b Relative distribution of most publishing countries. 
sity and the number of articles (Fig. 8b) was considerably lower with $r^{2}=0.20$, and the correlation was not significant with $p<0.67$.

China and Japan were the countries with the largest deviation with respect to the linear regression between $\mathrm{R} \& \mathrm{D}$ and the number of articles. They published rela- tively little in comparison with their $\mathrm{R} \& \mathrm{D}$ expenditures. In contrast, the UK published proportionally more. The USA, certainly outstanding regarding their absolute numbers, was in accordance with the regression line. Regarding the association between prevalence and the number of articles, the USA and the UK were close to the re-

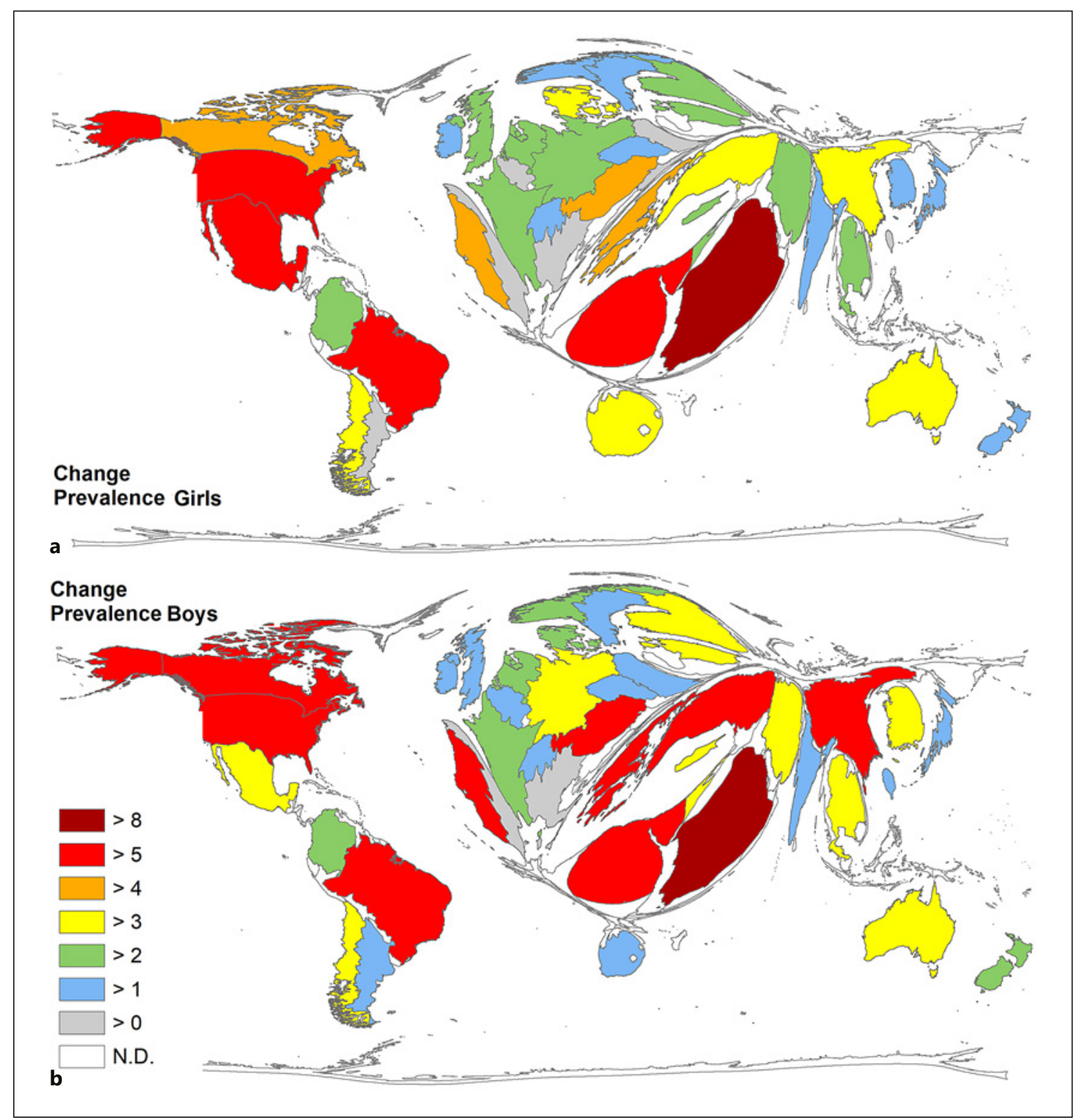

Fig. 6. Changes in the obesity prevalence in percent of children (2-19 years old) for countries with $\geq 30$ related articles [4]. a Girls. b Boys.

Fig. 7. Children (2-19 years old) obesity prevalence parameters for the countries. a Sex-standardized prevalence, $2015[4,24]$. b Sex-standardized prevalence, 2015 for countries with $\geq 30$ related articles [4, 24]. c Ratio of number of articles and prevalence of countries with $\geq 30$ related articles $\left(R_{\mathrm{PREV}}\right)$.

(For figure see next page.)

World Map of Childhood Obesity Research
Obes Facts 2021:14:382-396

DOI: $10.1159 / 000516777$ 


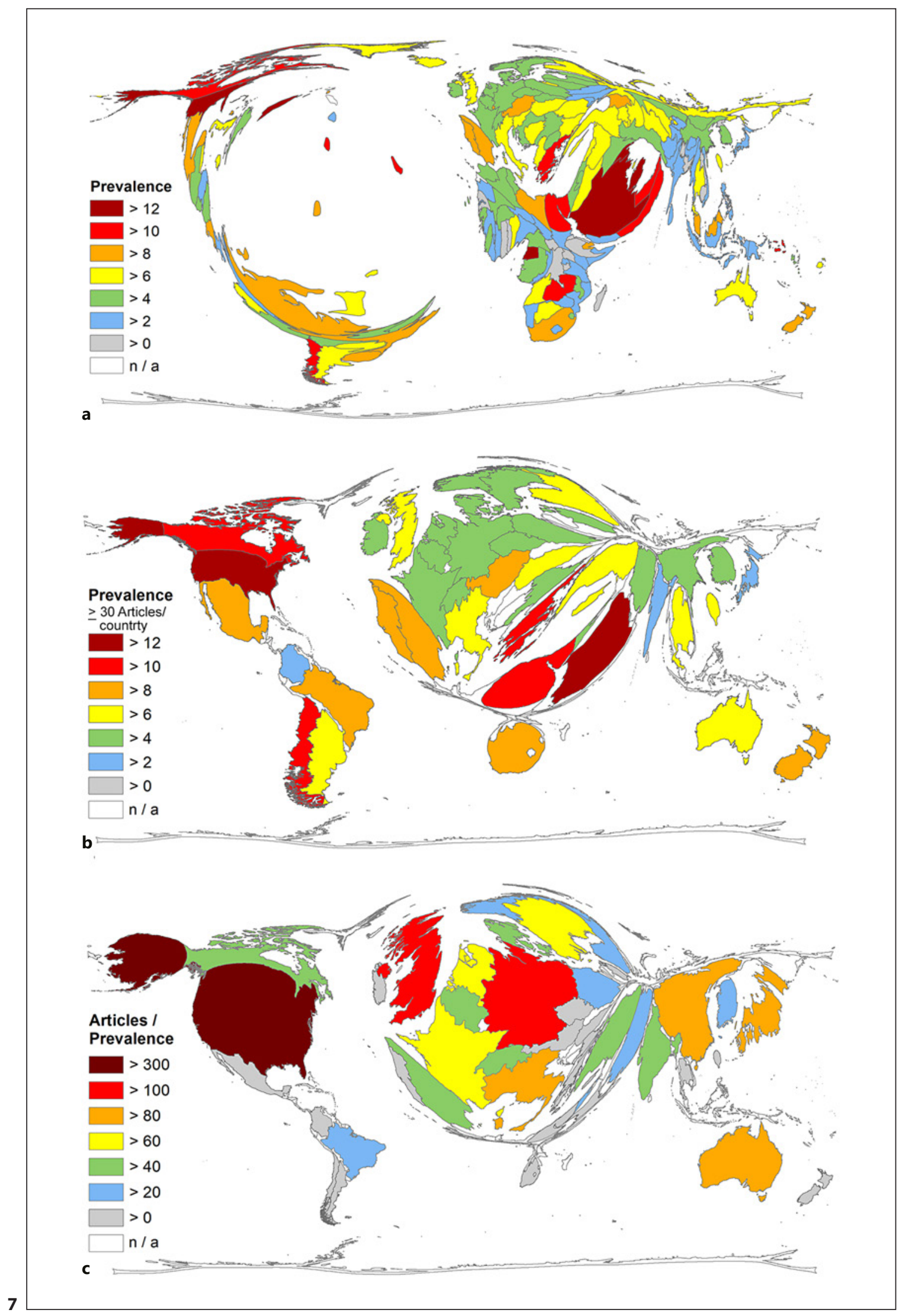


Fig. 8. OECD countries. a Expenditures for research and development 2015 in bn USD and the number of articles. $\mathbf{b}$ Sex-standardized prevalence of childhood obesity and the number of articles for countries with at least 30 related articles $[4,24,25]$.
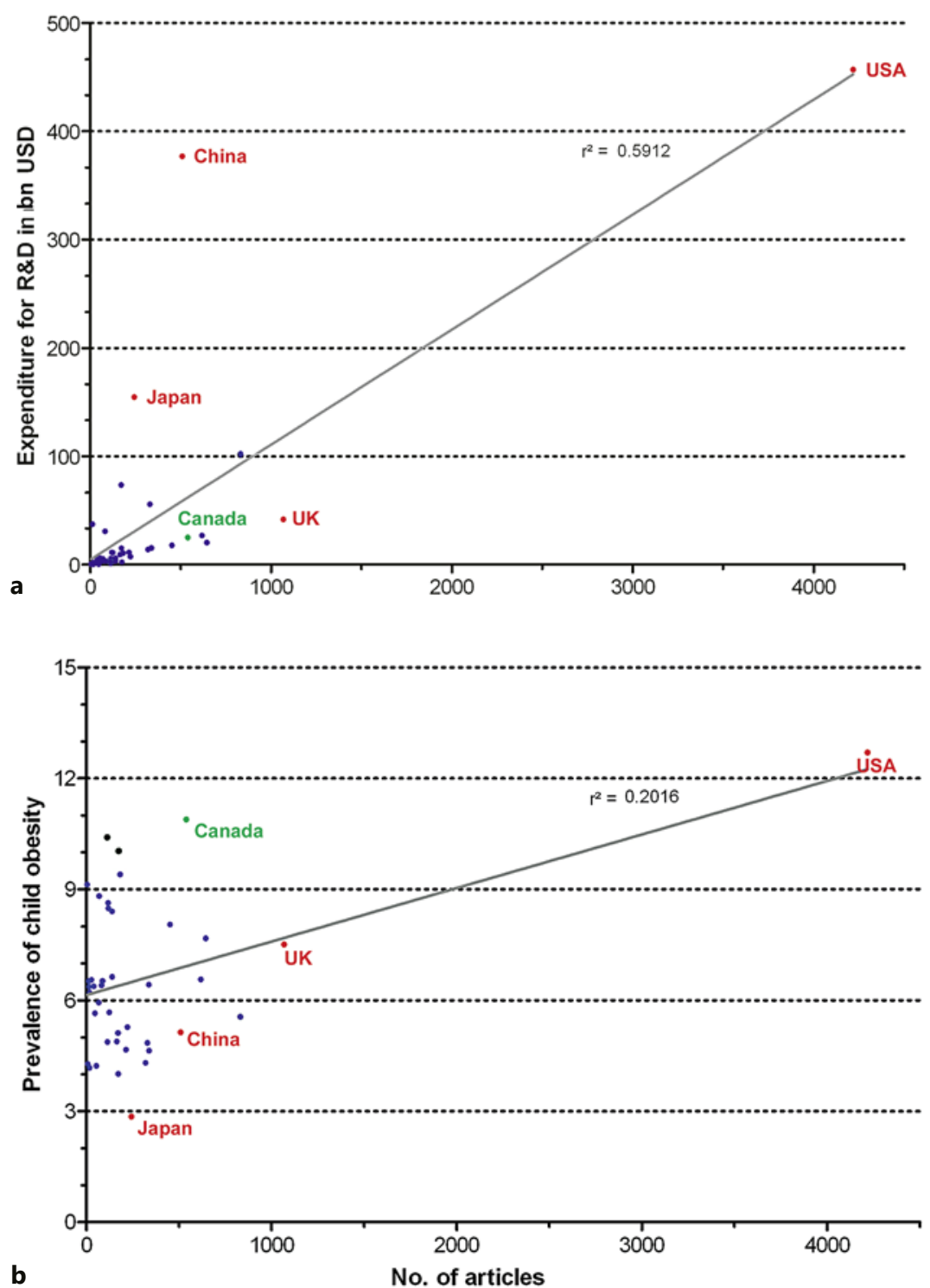

gression line, whereas China and Japan had a higher publication output relative to prevalence.

\section{Discussion}

The present study shows the current status, the development over time, and the trends of the global research output on childhood obesity. The development of publication numbers resembles the general scientific trend worldwide [26] in that it shows exponential growth. In contrast to the usual development, however, the numbers have only been rising more steeper since the beginning of the 2000s. The number of other biomedical topics started to increase steeply in the 1990s. This discrepancy reveals the delayed awareness of the dangerous effects of childhood obesity. Also, compared to overall obesity research, which increased significantly in the mid-80s onward, the importance of childhood obesity received little attention during this time [27].

In European countries, obesity has even been in the focus of the research interest since the second half of the 
20th century. Our results also show that Europe dominated research on childhood obesity in the 1970s, with Italy second only to the USA. Italy remained on this position until the end of the 1990s.

In the early publications, the research field of Pediatrics and General Medicine, that is, metabolism, dominated the scientific spectrum, while the nutritional perspective remained more or less uncared for. The role of dietetics did not arouse the interest of scientists until the 1980s. The research area $\mathrm{PEOH}$ also did not come into greater focus in the 1990s. The analysis of the author's keywords confirms this finding by pointing to terms such as prevalence, risk factors, and prevention as examples of recent research.

The geographic distribution of pediatric obesity research also basically follows the pattern of previous studies $[19,28,29]$. Accordingly, a clear dominance of the USA and European countries can be shown. This is why the evaluation of an existing association between countries' publication performance and prevalence seems justified. Highly affected countries should participate in research on a pro rata basis to be perceived with their respective individual specifications and backgrounds. Our findings show that despite a significant level of correlation, the coefficient of determination is relatively low, so that a clear causal correlation between country prevalence and publication output can be doubted.

Canada even showed a negative association. Its prevalence level and its incline are among the countries with the most negative developments [4], although its expenses for R\&D are comparably high. It was not until 2011 that the Canadian government launched a national dialog that led to the implementation of a political framework to address this shortcoming [30]. In the same year, publication numbers rose to $>20$ articles per year for the first time. Future analyses will show whether Canada's political aspirations will change the research landscape. In this respect, an analysis of socioeconomic influences seems promising.

The clearly visible North-South and West-East gradient in terms of the ratio of the number of articles to the prevalence rate is interrupted in South America by Brazil. Brazil is one of the countries with the highest prevalence and increase rates.

Basically, countries with the highest prevalence burdens are weakly represented in the research landscape, such as Polynesian or Micronesian and Middle East countries. Saudi Arabia has the highest prevalence and the highest rate of increase rate. It has become one of the fastest growing economies in the world, with the correspond- ing access to fast food and entertainment technologies and the associated lack of physical activity [31]. Leaving domestic chores to domestic workers may have also contributed to the increase of childhood obesity [32]. With 53 articles on childhood obesity since 2000 and steadily increasing numbers, Saudi Arabia is trying to meet the requirements of the disease burden.

Striking in terms of publication performance is Turkey, which ranked 10th. Despite the comparably moderate prevalence level of Turkish children, the increase, especially among boys, is alarming. Turkish studies on childhood obesity have gained prominence since 2000 . However, most regional prevalence studies were conducted from 2005 to 2011 and gradually declined thereafter [33].

Generally, the change in lifestyles toward a Western living, as well as the continued increase in urban densification and rural exodus in developing and emerging countries, is leading to an increase in childhood obesity. Additionally, the influence of oriental eating habits and customs is well discussed $[7,34]$. In this context, the Diabetes and ObesityManagement at the School(DOMATES) program, founded by the Turkish Government, and the Pediatric and Endocrinology and Diabetes Association deserve special mention. It aims to develop healthier eating habits and promote more activity in schools [7]. Banning the sale of high-energy, low-nutrient drinks and fried food in Turkish schools as well as advertising obesogenic food before and after children's television shows are also successes in reducing high-calorie diets. However, these are only small steps that should be complemented by a multidisciplinary set of measures worldwide.

Colombia is another country that does not usually rank high in terms of publication performance, but stands out in terms of research on childhood obesity. The prevalence of childhood obesity is currently stagnant at a high level with a sharp increase between 1980 and 2015. Colombia achieved a very high citation rate for their publications on childhood obesity, but with 35 articles, it was only just above the methodological analysis threshold of 30 articles. This is due to participation in some highly cited articles. Colombia collaborated in the Global Burden of Disease Study (2013) along with 186 other countries, including Saudi Arabia, which ranked second in citation rates. With 2,468 citations at the time of analysis, this study is identified as a highly cited article in WoS, showing great influence [35]. Colombia also took part in the International Study of Childhood Obesity, Lifestyle, and the Environment (ISCOLE), a multinational collaboration that aims to identify the links between lifestyle and 
obesity to gain a better understanding and increase research capacity and infrastructure [36]. Another international cooperation, the participation in the NCD-RisC study, has not yet had an influence on Colombia's citation rate, as the article is still too young to be able to generate its presumably high future [4].

Tran et al. [37] found that international scientific cooperation on childhood obesity is mainly based on cultural and geographic proximity. They also showed the disproportionality between the publication numbers and the affection of childhood obesity in several countries [37]. In line with our findings of the present study, Tran et al. [37] also emphasized the importance of international networks, especially to achieve ambitious national goals that require large-scale, contextualized interventions. International study groups have already proven their worth.

The expansion of international partnerships appears to be beneficial for future planning. The need for internationally comparable and reliable research is undoubtedly there. More targeted studies should be conducted. The development of prevention strategies and sensible treatments is mandatory. Based on this, the results of this study provide the necessary background for researchers, funders, and decision makers to minimize the risk of childhood obesity worldwide.

To better assess these results, some methodological limitations have to be considered. First, the use of the WoS database as well as the applied title search reduces the number of entries. However, the methodological advantage of a resulting more representative database outweighs the smaller amount of data. Second, the English bias of WoS should be taken into account. In addition, the findings on the correlation of R\&D expenditures cannot provide information on funding sources due to the lack of data.

\section{Conclusions}

Given the still alarming rates of increase and high levels of childhood obesity worldwide, it is necessary to look at the development and efforts of childhood obesity research to set the appropriate goals and trends for future research. The driving incentives of countries' research efforts are financial and infrastructural rather than based on epidemiological needs. Therefore, to address the epidemiological burden of disease, it is irrefutable that the most publishing countries need to build a larger network and strong international partnerships with, especially,

highly affected regions. In this regard, cultural and regional differences should be taken into account if the global epidemic of childhood obesity is to be successfully tackled. Internationally networked scientific knowledge can help better define regional goals for healthier eating habits and lifestyles and underpin strategic research to reduce the burden of childhood obesity worldwide.

\section{Statement of Ethics}

Because this study is a retrospective analysis, ethical approval is not required under national guidelines as no humans or animals were involved.

\section{Conflict of Interest Statement}

The authors declare no conflicts of interest.

\section{Funding Sources}

No funding was provided for this study.

\section{Author Contributions}

D.K. and D.A.G. contributed to conception, design, and analyses. D.K., M.B., D.Q., D.B., and D.A.G. contributed to the interpretation of data. D.K. drafted the article. D.K., M.B., D.Q., D.B., and D.A.G. revised the article. D.K., M.B., D.Q., D.B., and D.A.G. have participated in the final approval of the manuscript.

\section{References}

Obes Facts 2021;14:382-396

DOI: $10.1159 / 000516777$
1 WHO. Obesity - preventing and managing the global epidemic: report of a WHO consultation. WHO technical report series 894 . Geneva, Switzerland: WHO Library Cataloguing-in-Publication Data; 2000.

2 Sassi F. OECD library, the social dimensions of obesity. 2010. Available from: https://read. oecd-ilibrary.org/social-issues-migrationhealth/obesity-and-the-economics-of-prevention/the-social-dimensions-ofobesity_9789264084865-8-en\#page1 Accessed 2018 June.

3 GBD ObesityCollaborators. Health effects of overweight and obesity in 195 countries over 25 years. N Engl J Med. 2017 Jul 6;377(1):13-27.

4 NCD Risk Factor Collaboration. Worldwide trends in body-mass index, underweight, overweight, and obesity from 1975 to 2016: a pooled analysis of 2416 population-based measurement studies in 128.9 million children, adolescents, and adults. Lancet. 2017 Dec 16;390(10113):2627-42. 
5 Brophy S, Cooksey R, Gravenor MB, Mistry R, Thomas N, Lyons RA, et al. Risk factors for childhood obesity at age 5: analysis of the millennium cohort study. Bmc Public Health. 2009 Dec 16;9:467.

6 Inge TH, King WC, Jenkins TM, Courcoulas AP, Mitsnefes M, Flum DR, et al. The effect of obesity in adolescence on adult health status. Pediatrics. 2013 Dec;132(6):1098-104.

7 Bereket A, Atay Z. Current status of childhood obesity and its associated morbidities in Turkey. J Clin Res Pediatr Endocrinol. 2012 Mar;4(1):1-7.

8 Lee H, Pantazis A, Cheng P, Dennisuk L, Clarke PJ, Lee JM. The association between adolescent obesity and disability incidence in young adulthood. J Adolesc Health. 2016 Oct; 59(4):472-8.

9 Taber DR, Chriqui JF, Powell L, Chaloupka FJ. Association between state laws governing school meal nutrition content and student weight status: implications for new USDA school meal standards. JAMA Pediatr. 2013 Jun;167(6):513-9.

10 Ordonez-Betancourth J, Jepson R, Bhopal R. How have authors from five ethnically diverse countries included and supported ethnicity and race in childhood obesity research? Eur J Public Health. 2018 May;28:79-80.

11 Frayling TM, Timpson NJ, Weedon MN, Zeggini E, Freathy RM, Lindgren CM, et al. A common variant in the FTO gene is associated with body mass index and predisposes to childhood and adult obesity. Science. 2007 May 11;316(5826):889-94.

12 Silventoinen K, Jelenkovic A, Sund R, Hur YM, Yokoyama Y, Honda C, et al. Genetic and environmental effects on body mass index from infancy to the onset of adulthood: an individual-based pooled analysis of 45 twin cohorts participating in the COllaborative project of development of anthropometrical measures in twins (CODATwins) study. Am J Clin Nutr. 2016 Aug;104(2):371-9.

13 Sun WF, Dong H, Becker AS, Dapito DH, Modica S, Grandl G, et al. Cold-induced epigenetic programming of the sperm enhances brown adipose tissue activity in the offspring. Nat Med. 2018 Nov;24(11):1776.

14 Wang Y, Moreno LA, Caballero B, Cole TJ. Limitations of the current world health organization growth references for children and adolescents. Food Nutr Bull. 2006 Dec;27(4 Suppl Growth Standard):S175-88.
15 Bornmann L, Leydesdorff L. Scientometrics in a changing research landscape. Embo Rep. 2014 Dec;15(12):1228-32.

16 Groneberg-Kloft B, Fischer TC, Quarcoo D, Scutaru C. New quality and quantity indices in science (NewQIS): the study protocol of an international project. J Occup Med Toxicol. 2009 Jun 26;4:16.

17 Groneberg DA, Froehlich A, Klingelhofer D, Bundschuh M, Ohlendorf D. Analysis of the research architecture on the burnout syndrome. Zentralblatt Arb Arb. 2016 Jan;66(1): $1-9$.

18 Koster C, Klingelhofer D, Groneberg DA, Schwarzer M. Rotavirus - global research density equalizing mapping and gender analysis. Vaccine. 2016 Jan 2;34(1):90-100.

19 Bruggmann D, Alafi A, Jaque J, Klingelhofer $\mathrm{D}$, Bendels $\mathrm{MH}$, Ohlendorf $\mathrm{D}$, et al. Worldwide research architecture of vitamin D research: density-equalizing mapping studies and socio-economic analysis. Nutr J. 2018 Jan 6;17(1):3.

20 Gastner MT, Newman ME. From the cover: diffusion-based method for producing density-equalizing maps. Proc Natl Acad Sci U S A. 2004 May 18;101(20):7499-504.

21 Oppenheimer K. The proportion of food to body weight and body surface area in infants. Z Biol-Munich. 1901;24:147-60.

22 Cole TJ, Bellizzi MC, Flegal KM, Dietz WH. Establishing a standard definition for child overweight and obesity worldwide: international survey. BMJ. 2000 May 6;320(7244): 1240-3.

23 Barlow SE. Expert committee recommendations regarding the prevention, assessment, and treatment of child and adolescent overweight and obesity: summary report. Pediatrics. 2007 Dec;120:S164-S92.

24 CIA. The world factbook, sex ratio. 2018. Available from: https://www.cia.gov/library/ publications/the-world-factbook/fields/2018. html Accessed 2018 Apr.

25 OECD. OECD data, research and development statistics (RDS). 2018. Available from: http: //www.oecd.org/innovation/inno/researchanddevelopmentstatisticsrds.htm Accessed 2018 May.

26 Van Noorden R. Global scientific output doubles every nine years. Naturecom, news blog. 2014. Available from: blogsnaturecom Accessed 2018 Jun.
27 Groneberg DA, Franke K, Klingelhofer D, Schwarzer M, Ohlendorf D. Density equalizing mapping of obesity: analysis of a global epidemic. Z Gastroenterol. 2015 Jun;53(6): 553-61.

28 Schreiber M, Klingelhofer D, Groneberg DA, Bruggmann D. Patient safety: the landscape of the global research output and gender distribution. BMJ Open. 2016 Feb 12;6(2):e008322.

29 Schoffel N, Gfroerer S, Rolle U, Bendels MH, Klingelhofer D, Groneberg-Kloft B. Hirschsprung disease: critical evaluation of the global research architecture employing scientometrics and density-equalizing mapping. Eur J Pediatr Surg. 2017 Apr;27(2):18591.

30 IPCC. The intergovernmental panel on climate change. 2019. Available from: https:// www.ipcc.ch Accessed 2019 Dec.

31 Badran M, Laher I. Type II diabetes mellitus in arabic-speaking countries. Int J Endocrinol. 2012;2012:902873.

32 Hammad SS, Berry DC. The child obesity epidemic in Saudi Arabia: a review of the literature. J Transcult Nurs. 2017 Sep;28(5):50515.

33 Alper Z, Ercan I, Uncu Y. A meta-analysis and an evaluation of trends in obesity prevalence among children and adolescents in Turkey: 1990 through 2015. J Clin Res Pediatr E. 2018 Mar;10(1):59-67.

34 Kirchengast S, Schober E. [Migration as risk factor of overweight and adipositas in children and adolescents]. Anthropol Anz. 2006 Dec;64(4):411-21.

$35 \mathrm{Ng} \mathrm{M}$, Fleming T, Robinson M, Thomson B, Graetz N, Margono C, et al. Global, regional, and national prevalence of overweight and obesity in children and adults during 19802013: a systematic analysis for the global burden of disease study 2013. Lancet. 2014 Aug; 384(9945):766-81.

36 Katzmarzyk PT, Barreira TV, Broyles ST, Champagne CM, Chaput JP, Fogelholm M, et al. The international study of childhood obesity, lifestyle and the environment (ISCOLE): design and methods. Bmc Public Health. 2013 Sep 30;13:900.

37 Tran BX, Dang KA, Le HT, Ha GH, Nguyen $\mathrm{LH}$, Nguyen TH, et al. Global evolution of obesity research in children and youths: setting priorities for interventions and policies. Obesity Facts. 2019;12(2):137-49. 